\title{
Correlation of Anti-Müllerian Hormone with Polycystic Ovarian Disease and its Relation with Age
}

\author{
Sara Omer Muhammed \\ Obstetrics and Gynecology \\ Sulaimani Maternity Teaching Hospital \\ Sulaimani, Iraq \\ sararashan87@yahoo.com
}

\author{
Chro Najmaddin Fattah \\ Obstetrics and Gynecology \\ Sulaimani Maternity Teaching Hospital \\ School of Medicine/ University of Sulaimani \\ Sulaimani, Iraq \\ chrofattah@yahoo.co.uk
}

Volume 4 - Special Issue:

3rd International

Conference on Health \& Medical Sciences: Insight into Advanced Medical Research (ICHMS 2019)

DOI:

10.24017/science.2019

.ICHMS.5

Received:

12 June 2019

Accepted:

5 July 2019

\section{Abstract}

Polycystic ovarian disease (PCOD) is common endocrine disorder of reproductive-aged women. Serum Anti-Müllerian hormone (AMH) increases in PCOD women due to increased follicle numbers. Objectives: The aim was to evaluate ovarian reserve by measuring level of AMH among PCOD women. Prospective cohort study was performed on 62 ladies who aged 25 to 40 years and diagnosed by Rotterdam criteria as PCOD in Sulaimani Maternity Teaching Hospital/Outpatient Gynecological Clinic during May 2018 to May 2019. Consents were obtained from patients for their inclusion. Inclusion criteria were age of 25-40 years and diagnosis of PCOD. The patients' ages, body mass index (BMI) and level of AMH were recorded. Sample size estimation was performed by "GPower 3.1" and "IBM SPSS Statistics version 25" was used for analysis of data. P-value of $(\leq 0.05)$ was considered significant. The mean $\pm S D$ (standard deviation) of age of women were $31.7 \pm 5$ years. The majority of participants were housewives from inside of Sulaimani City and most of them were diagnosed to have PCOD through clinical features and results of ultrasonography. The mean $\pm S D$ of $B M I$ and $A M H$ were $26.2 \pm 2.8 \mathrm{~kg} / \mathrm{m}^{2}$ (ranged from 21.3 to $33.2 \mathrm{~kg} / \mathrm{m}^{2}$ ) and $4.76 \pm 3.51 \mathrm{ng} / \mathrm{ml}$ (ranged from $0.1-14.6 \mathrm{ng} / \mathrm{ml}$ ) respectively. There was significant association between age of the participants and $A M H$ and the association of BMI and $A M H$ was not significant. The level of AMH is decreased with aging and it is higher among PCOD women due to increased follicle numbers. The level of AMH was not associated with BMI.

Keywords: Anti-Müllerian hormone (AMH), Infertility, Polycystic ovarian disease (PCOD). 


\section{INTRODUCTION}

Polycystic ovarian disease (PCOD) is a common endocrine disorder of reproductive-aged women and it accounts for $10-20 \%$ of women in such ages [1]. Moreover, it is a common cause of infertility and it is usually diagnosed at fertility clinics [2]. It is a condition of chronic anovulation and hyperandrogenism, and it is associated with menstrual disruption, obesity, insulin resistance and lipid abnormalities [3]. Women with PCOD, especially those with hyperandrogenism and/or obesity, have metabolic disturbances more frequently; therefore, this make them to be more prone to metabolic syndromes and their Anti-Müllerian hormone (AMH) will be elevated [4].

The diagnosis of PCOD can be made by Rotterdam criteria if woman had at least two of the following three criteria: clinical or biochemical hyperandrogenism, oligo-ovulation or anovulation, and polycystic ovarian morphology on ultrasonography which is defined as the presence of more than 12 follicles of two to nine millimeters in diameter each, or ovarian volume of greater than 10 cubic centimeters [5].

Serum AMH is used as a marker for the diagnosis of PCOD [6]. AMH is a member of the transforming growth factor beta (TGF-beta) protein superfamily and exclusively produced by the gonads [2]. Serum AMH concentration increases in PCOD due to the increased numbers of follicles in PCOD and it reflects the size of the pool of these follicles [6]. The AMH level is associated with arrested follicular pool and serves as marker of follicle counts [6]. Moreover, it has the properties of follicle stimulating hormone (FSH) inhibition; therefore, it counteracts the action of gonadotrophin [7]. In addition, AMH participates in the process of folliculogenesis and it is glycoprotein produced and secreted by the granulosa cells of the early primordial follicles [2]. Thereafter, the secretion of AMH increases and reaches the peak concentration in small antral follicles before it subsides in the granulosa cells of the preovulatory follicles [2].

Studies showed that serum AMH levels in women with PCOD are two to three times higher than women with normal ovaries [7]. Although serum AMH level is high in women with PCOD, its reference range is variable [1]. Moreover, serum AMH level does not change during the menstrual cycle and it is not affected by oral contraceptive use; thence, blood sample can be taken at any time of the month [7].

The follicles' number decrease with advance in age in both patients with PCOD and normal ovulatory women; therefore, as patients with PCOD have greater initial pool of follicles, their ovarian reserve is unlikely to undergo rapid depletion [7].

In the current study, we tried to evaluate ovarian reserve by measuring AMH level among women with PCOD who aged from 25 to 40 years old.

\section{METHODS AND MATERIALS}

We performed a prospective cohort study on 62 ladies who were aged 25-40 years and diagnosed by Rotterdam criteria as PCOD in the Sulaimani Maternity Teaching Hospital/Outpatient Gynecological Clinic during May 2018 to May 2019. Concurrently, the women were randomly selected by using simple random sampling method.

Research Ethical Committee of Kurdistan Board of Medical Specialties (KBMS) approved the study proposal and a formal acceptance letter was obtained from Sulaimani Maternity Teaching Hospital before starting the study. In addition, written informed consent has also been taken from the patients for their inclusion in this study.

The inclusion criteria were women who were aged 25-40 years old and diagnosed by Rotterdam criteria as PCOD.

Serum Anti-Müllerian hormone (AMH) was used as a marker for the assessment of PCOD; blood samples were taken and sent for laboratory. In addition, the researchers had borne the cost of the test. The ages, BMI, residencies, and occupations of the participants were also recorded. 
Sample size estimation was performed by using "GPower 3.1" program and it yielded 60 samples when the effect size of 0.5 , P-value of $\leq 0.05$, and study power of $>95 \%$ were selected. Therefore, the sample size of 62 participants was collected. Furthermore, the "IBM SPSS Statistics version 25" was used for the analysis of the data and both descriptive and inferential statistics were used. Moreover, P-values of $(\leq 0.05$, and $<0.001)$ were considered as statistically significant, and highly significant associations, consecutively. In addition, Pearson Chi-Square was used to find out the significancy of association between independent and dependent variable pairs, and Pearson R Correlation was used to calculate the direction of the correlation between the two variables.

\section{RESULTS}

The mean \pm SD (standard deviation) of the age of participants were $31.7 \pm 5$ years (ranged from 25-40 years).

Most of the participants were diagnosed to have PCOD through clinical features and results of ultrasonography (Table 1).

Table (1): The frequencies of diagnostic methods among age groups

\begin{tabular}{lccccc}
\hline \multirow{2}{*}{ Diagnostic methods } & \multicolumn{3}{c}{ Age groups (year) (\%) } & \multirow{2}{*}{ Total (\%) } \\
\cline { 3 - 5 } & & $\mathbf{2 5 - 3 0}$ & $\mathbf{3 1 - 3 5}$ & $\mathbf{3 6 - 4 0}$ & \\
\hline Clinical & Yes & $27(43.5)$ & $17(27.4)$ & $18(29)$ & $62(100 \%)$ \\
\hline \multirow{2}{*}{ Biochemical } & Yes & $15(24.2)$ & $8(12.9)$ & $8(12.9)$ & $31(50 \%)$ \\
\hline \multirow{2}{*}{ Ultrasonography } & No & $12(19.4)$ & $9(14.5)$ & $10(16.1)$ & $31(50)$ \\
\cline { 2 - 5 } & Yes & $24(38.7)$ & $16(25.8)$ & $17(27.4)$ & $57(91.9)$ \\
\hline
\end{tabular}

The majority of the participants were from inside of the Sulaimani City and housewives (Table 2).

Table (2): the distribution of demographic features among participants' age groups

\begin{tabular}{cccccc}
\hline \multirow{2}{*}{ Demographic features } & \multicolumn{3}{c}{ Age groups (year) (\%) } & \multirow{2}{*}{ Total (\%) } \\
\cline { 2 - 5 } Residencies & Inside city & $25-30$ & $31-35$ & $36-40$ & \\
\cline { 2 - 5 } & Outside city & $22(35.5)$ & $12(19.4)$ & $11(17.7)$ & $45(72.6)$ \\
\hline & Teacher & $5(8.1)$ & $5(8.1)$ & $7(11.3)$ & $17(27.4)$ \\
\cline { 2 - 5 } & Student & $5(8.1)$ & $2(3.2)$ & $5(8.1)$ & $12(19.4)$ \\
\cline { 2 - 5 } Occupation & Housewife & $10(6.5)$ & $0(0)$ & $0(0)$ & $4(6.5)$ \\
\cline { 2 - 5 } & Nurse & $1(1.6)$ & $9(14.5)$ & $9(14.5)$ & $28(45.2)$ \\
\cline { 2 - 5 } & Lawyer & $2(3.2)$ & $1(1.6)$ & $2(3.2)$ & $4(6.5)$ \\
\cline { 2 - 5 } & Employee & $3(4.8)$ & $3(4.8)$ & $1(1.6)$ & $4(6.5)$ \\
\cline { 2 - 5 } & Engineer & $2(3.2)$ & $0(0)$ & $0(0)$ & $2(3.2)$ \\
\cline { 2 - 5 } & Hairdresser & $0(0)$ & $1(1.6)$ & $0(0)$ & $1(1.6)$ \\
\hline
\end{tabular}

The mean \pm SD of BMI was $26.2 \pm 2.8 \mathrm{~kg} / \mathrm{m}^{2}$ (ranged from 21.3 to $33.2 \mathrm{~kg} / \mathrm{m}^{2}$ ). While the mean \pm SD of the AMH were $4.76 \pm 3.51 \mathrm{ng} / \mathrm{ml}$ (ranged from $0.1-14.6 \mathrm{ng} / \mathrm{ml}$ ).

There was statistically highly significant association between age of the participants and $\mathrm{AMH}$, and the direction of the association was negative i.e. AMH decreased when the age of the women increased (Table 3). 
Table (3): the association of age of the participants with AMH

\begin{tabular}{|c|c|c|c|c|c|}
\hline \multirow{2}{*}{$\begin{array}{c}\text { Age } \\
\text { groups } \\
\text { (year) }\end{array}$} & \multicolumn{3}{|c|}{ AMH (ng/ml) } & \multirow{2}{*}{$\begin{array}{c}\text { Total } \\
\text { (\%) }\end{array}$} & \multirow{2}{*}{$\begin{array}{c}\text { P-value } \\
\text { (Pearson's R } \\
\text { Correlation) } \\
\end{array}$} \\
\hline & $\begin{array}{c}\text { Low }(<0.7) \\
(\%)\end{array}$ & $\begin{array}{c}\text { Normal (0.7-3) } \\
(\%)\end{array}$ & High (>3) (\%) & & \\
\hline $25-30$ & $0(0)$ & $5(8.1)$ & 22 (35.5) & $\begin{array}{c}27 \\
(43.6) \\
\end{array}$ & \multirow{4}{*}{$<0.001(-0.597)$} \\
\hline $31-35$ & $0(0)$ & $3(4.8)$ & $14(22.6)$ & $\begin{array}{c}17 \\
(27.4)\end{array}$ & \\
\hline $36-40$ & $4(6.5)$ & 12 (19.6) & $2(3.2)$ & $18(29)$ & \\
\hline Total & $4(6.5)$ & $20(32.3)$ & 38 (61.3) & $\begin{array}{c}62 \\
(100)\end{array}$ & \\
\hline
\end{tabular}

There was statistically insignificant association between BMI of the participants and AMH (Table 4).

Table (4): the association of BMI with AMH

\begin{tabular}{|c|c|c|c|c|c|}
\hline \multirow[b]{2}{*}{ BMI (kg/m²) } & \multicolumn{3}{|c|}{ AMH (ng/ml) } & \multirow[b]{2}{*}{ Total (\%) } & \multirow{2}{*}{$\begin{array}{c}\text { P-value } \\
\text { (Pearson's R } \\
\text { Correlation) }\end{array}$} \\
\hline & Low $(<0.7)(\%)$ & $\begin{array}{c}\text { Normal (0.7-3) } \\
(\%)\end{array}$ & $\begin{array}{c}\text { High (>3) } \\
(\%)\end{array}$ & & \\
\hline $\begin{array}{l}\text { Normal (18.5- } \\
24.9)\end{array}$ & $2(3.2)$ & $4(6.5)$ & $15(24.2)$ & 21 (33.9) & \multirow{4}{*}{$0.144(0.046)$} \\
\hline $\begin{array}{l}\text { Overdose (25- } \\
\text { 29.9) }\end{array}$ & $2(3.2)$ & $15(24.2)$ & $16(25.8)$ & $33(53.2)$ & \\
\hline Obese (>30) & $0(0)$ & $1(1.6)$ & $7(11.3)$ & $8(12.9)$ & \\
\hline Total & $4(6.5)$ & $20(32.3)$ & 38 (61.3) & $62(100)$ & \\
\hline
\end{tabular}

\section{DISCUSSION}

As we mentioned in our inclusion criteria, all of the patients were afflicted with PCOD. In addition, the methods of diagnosis were as follows: clinical diagnosis (100\%), diagnosis on the bases of ultrasonography findings (91.9\%), and biochemistry findings (50\%) as shown in (Table 1). All the methods were used together to diagnose women with PCOD. Furthermore, these diagnostic methods were used according to the three criteria of Rotterdam [5].

The ages of the women were ranged from 25 to 40 years (mean $\pm \mathrm{SD}=31.7 \pm 5$ ), and most of them were housewives from inside the city of Sulaimani (Table 2). During the reproductiveaged period, AMH in women is secreted by granulose cells of small antral follicles of the ovaries [2]. Furthermore, it is not detected until the age of puberty and it reaches the highest level at the age of 24.5 years; therefore, $\mathrm{AMH}$ is age related [8]. The quality and number of oocytes will decline with advance in age; herein, the level of AMH will decline to the lowest during menopause and later is not detected at all [6]. Thence, it can be used as a good predictor of ovarian reserve and antral follicle count [9]. Although the ages of the patients in the current study were during their reproductive period, the level of AMH was declined with the advancement of the ages in this period too and their association was statistically highly significant (Table 3). Moreover, the same finding was found in the literature we searched such as the systematic review performed by Homburg et al. at 2014 in London [2], the study of Köninger et al. at 2018 in Germany [6], the study of Barbakadze et al. at 2014 in Georgia [8], and the study of Shi et al. at 2018 in China [9].

The mean \pm SD of BMI was $26.2 \pm 2.8 \mathrm{~kg} / \mathrm{m}^{2}$ (range; 21.3 to $33.2 \mathrm{~kg} / \mathrm{m}^{2}$ ) and the mean \pm SD of AMH level was $4.76 \pm 3.51 \mathrm{ng} / \mathrm{ml}$ (range; 0.1 to $14.6 \mathrm{ng} / \mathrm{ml}$ ). In addition, the results of current study showed no significant association between BMI and AMH (Table 4). This association was also statistically insignificant between overweight and obesity with the level of AMH in the literature we searched, i.e. the level of AMH was stable despite the trial of reduction in the body weights of PCOD women as shown by the study of Moini et al. [10] at 2018 in Tehran, Iran. We may explain the findings by the fact that the level of AMH is related to the number of follicles which are greater in number in patients with PCOD and the follicle numbers are 
not changed; increased or decreased, due to body weight as shown by the study of Köninger et al. [6] at 2018 in Germany. Moreover, the study of de Kat et al. [4] at 2015 in Netherlands mentioned that body weight may be increased due to metabolic disturbances that happen in women with PCOD.

Although all of the patients in this study were afflicted with PCOD, AMH level was above normal level in $61.3 \%$ of patients (Tables 3 and 4). Furthermore, the study of Tian et al. [11] at 2014 in China found about the same results although they were also included women without PCOD in their study. Interpretatively, this may be due to the fact that the numbers of follicles are increased in patients with PCOD although their numbers decrease with aging as normal women as it was shown by the study of Köninger et al. [6] at 2018 in Germany.

As we mentioned in our inclusion criteria, all of the patients were afflicted with PCOD. In addition, the methods of diagnosis were as follows: clinical diagnosis (100\%), diagnosis on the bases of ultrasonography findings (91.9\%), and biochemistry findings (50\%) as shown in (Table 1). All the methods were used together to diagnose women with PCOD. Furthermore, these diagnostic methods were used according to the three criteria of Rotterdam [5].

The ages of the women were ranged from 25 to 40 years (mean $\pm \mathrm{SD}=31.7 \pm 5$ ), and most of them were housewives from inside the city of Sulaimani (Table 2). During the reproductiveaged period, AMH in women is secreted by granulose cells of small antral follicles of the ovaries [2]. Furthermore, it is not detected until the age of puberty and it reaches the highest level at the age of 24.5 years; therefore, $\mathrm{AMH}$ is age related [8]. The quality and number of oocytes will decline with advance in age; herein, the level of $\mathrm{AMH}$ will decline to the lowest during menopause and later is not detected at all [6]. Thence, it can be used as a good predictor of ovarian reserve and antral follicle count [9]. Although the ages of the patients in the current study were during their reproductive period, the level of AMH was declined with the advancement of the ages in this period too and their association was statistically highly significant (Table 3). Moreover, the same finding was found in the literature we searched such as the systematic review performed by Homburg et al. at 2014 in London [2], the study of Köninger et al. at 2018 in Germany [6], the study of Barbakadze et al. at 2014 in Georgia [8], and the study of Shi et al. at 2018 in China [9].

The mean \pm SD of BMI was $26.2 \pm 2.8 \mathrm{~kg} / \mathrm{m}^{2}$ (range; 21.3 to $33.2 \mathrm{~kg} / \mathrm{m}^{2}$ ) and the mean $\pm \mathrm{SD}$ of $\mathrm{AMH}$ level was $4.76 \pm 3.51 \mathrm{ng} / \mathrm{ml}$ (range; 0.1 to $14.6 \mathrm{ng} / \mathrm{ml}$ ). In addition, the results of current study showed no significant association between BMI and AMH (Table 4). This association was also statistically insignificant between overweight and obesity with the level of AMH in the literature we searched, i.e. the level of AMH was stable despite the trial of reduction in the body weights of PCOD women as shown by the study of Moini et al. [10] at 2018 in Tehran, Iran. We may explain the findings by the fact that the level of $\mathrm{AMH}$ is related to the number of follicles which are greater in number in patients with PCOD and the follicle numbers are not changed; increased or decreased, due to body weight as shown by the study of Köninger et al. [6] at 2018 in Germany. Moreover, the study of de Kat et al. [4] at 2015 in Netherlands mentioned that body weight may be increased due to metabolic disturbances that happen in women with PCOD.

Although all of the patients in this study were afflicted with PCOD, AMH level was above normal level in $61.3 \%$ of patients (Tables 3 and 4). Furthermore, the study of Tian et al. [11] at 2014 in China found about the same results although they were also included women without PCOD in their study. Interpretatively, this may be due to the fact that the numbers of follicles are increased in patients with PCOD although their numbers decrease with aging as normal women as it was shown by the study of Köninger et al. [6] at 2018 in Germany.

\section{CONCLUSION}

The level of AMH is age-related and it is higher among women with PCOD due to the increased numbers of follicles in women with this condition. Although its level is larger in PCOD women, its level will decrease with advancement of ages.

There was no significant statistical association between the BMI and the level of AMH. 


\section{REFERENCE}

[1] T. WONGWANANURUK, N. PANICHYAWAT ， S. INDHAVIVADHANA, M. RATTANACHAIYANONT, S. ANGSUWATHANA, K. TECHATRAISAK, $\quad$ ET $\quad$ AL. $\quad$ "ACCURACY OF ANTIMÜLLERIAN HORMONE AND TOTAL FOLLICLES COUNT TO DIAGNOSE POLYCYSTIC OVARYSYNDROME IN REPRO DUCTIVE WOMEN,” TAIWAN J OBSTET GYNECOL., VOL. 57, NO.. 4, PP. 499-506, 2018.

[2] R. HOMBurg, G. CRAWFORD. "ThE ROLE OF AMH IN ANOVUlATion ASSOCIATED WITH PCOS: A HYPOTHESIS,” HUM REPROD., VOL. 29, NO. 6, PP. 1117-1121, 2014.

[3] N. N. Jahromi, M. H. DabBaghmanesh, P. BaKhshaie, M. E. PArsanezhad, Z. AnVAR, M. Alborzi, ET AL. “ASSESSMENT OF OXYTOCIN LEVEL, GLUCOSE METABOLISM COMPONENTS AND CUTOFF VALUES FOR OXYTOCIN AND ANTI-MULLERIAN HORMONE IN INFERTILE PCOS WOMEN,” TAIWAN J OBSTET GYNECOL., VOL. 57, NO. 4, PP. 555-559, 2018.

[4] A. C. de Kat, F. J. Broekmans, J. S. Laven, Y. T. van der Schouw. "Anti-Müllerian Hormone as a marker of ovarian reserve in relation to cardio-metabolic health: A narrative review,” Maturitas, vol. 80, no. 3, pp. 251257, 2015.

[5] H. Aydoğmuş, S. Kelekçi, F. Elmalı, S. Aydoğmuş. "Can we use serum Anti-Mullerian hormone to differentiate the diagnosis between polycystic ovary syndrome patients and healthy women with polycystic ovarian morphology and regular menstrual cycles,” Saudi Med J., vol. 39, no. 10, pp. 1011-1016, 2018.

[6] A. Köninger, A. KAMPMEIER, B. SCHMidT, M. Frank, T. STROWITZKI, R. KimMig, ET AL. "TRENDS IN ANTIMÜLLERIAN HORMONE CONCENTRATIONS ACROSS DIFFERENT STAGES OF PREGNANCY IN WOMEN WITH POLYCYSTIC OVARY SYNDROME,” REPROD BIOMED ONLINE, VOL. 37, NO. 3, PP. 367-374, 2018.

[7] C. Y. Yue, L. K. Y. Lu, M. Li, Q. L. Zhang, C. M. Ying. "Threshold value of anti-Mullerian hormone for the diagnosis of polycystic ovary syndrome in Chinese women,” PLoS ONE, vol. 13, no. 8, pp. e0203129, 2018.

[8] L. Barbakadze, J. Kristasashvili. "Antimullerian hormone in cases of different reproductive pathologies," Georgian Med News, vol. 232-233, pp. 16-21, 2014.

[9] X. Shi, D. Peng, Y. Liu, X. Miao, H. Ye, J. Zhang. “Advantages of Serum Anti-Müllerian Hormone as a Marker for Polycystic Ovarian Syndrome,” Lab Med., vol. 00, pp. 1-7, 2018.

[10] A. Moini, A. Arabipoor, M. Hemat, J. Ahmadi, R. Salman-Yazdi, Z. Zolfaghari. "The effect of weight loss program on serum anti-Müllerian hormone level in obese and overweight infertile women with polycystic ovary syndrome," Gynecol Endocrinol, vol. 35, no. 2, pp. 119-123, 2019.

[11] X. Tian, X. Ruan, A. O. Mueck, D. Wallwiener, J. Wang, S. Liu, D. Yin, Y. Lu, Y. Zhang, H. Wu. "Serum anti-Mullerian hormone and insulin resistance in the main phenotypes of non-obese polycystic ovarian syndrome women in China,” Gynecol Endocrinol., vol. 30, no. 11, pp. 836-839, 2014. 